\title{
MATURITY ANALYSIS TO ASSESS THE CAPABILITY OF AN ORGANIZATION TO INNOVATE
}

\author{
Marc Adam, Marco Peter and Stella Gatziu Grivas \\ University of Applied Sciences Northwestern Switzerland
}

\begin{abstract}
Globalization creates a highly competitive environment for organizations. To be successful in this environment in the long term, organizations need the capability to innovate and produce ongoing innovations. However, many organizations do struggle to do so despite their innovation efforts. Therefore, it is important to determine the factors of a company's innovation capability. This research paper answers the question of how a method should be designed in order to assess an organization's capability to innovate. To answer this question, extensive literature research on the topics of innovation, existing innovation models, and organizational behavior, as well as expert interviews with people from different industries, were conducted. Thus, this paper follows a design science strategy with a qualitative approach. The analysis of the literature showed that several factors determine the innovation capability of an organization. However, existing models sometimes focus on a single factor or contain several factors, which are not described sufficiently. Furthermore, the possibility for organizations to assess themselves using the models is largely missing. Based on the data from the literature and the interviews, a maturity assessment, consisting of a model of seven dimensions and 27 indicators, and a corresponding questionnaire to assess these indicators, was developed. The research findings suggest that the developed maturity assessment with its Organizational Innovation Capability model is a suitable and comprehensive method that can be used to support organizations by assessing their current innovation capability in order to define the necessary further measures. This research argues that the additional dimensions and indicators are needed in order to provide a comprehensive overview of the innovation capability maturity of an organization. Further, the experts emphasized the value of creating awareness within an organization and providing a good foundation for further discussions and actions by means of the maturity assessment.
\end{abstract}

\section{KEYWORDS}

Innovation, Innovation Capabilities, Innovation Capability Assessment, Maturity Assessment

\section{INTRODUCTION}

Innovation is everywhere, in the world of goods as well as in the world of words (Benoit, 2008). Innovation is therefore not only discussed in technical literature but also in social sciences such as history, sociology, management, and economics as well as in the humanities and arts. Nowadays, innovation has become a symbol of our society and is seen as a panacea for overcoming our problems (Benoit, 2008). However, today many consider innovation to be a technological and economic issue. This is reflected, for example, in the fact that most government studies such as the OECD's Oslo Manual (OECD, 2005) focus exclusively on innovation in enterprises.

The fast-paced technological progress has led to the integration of the world's economies into a single market within the last quarter of the $20^{\text {th }}$ century and further has become a major factor in the process of change known as globalization (Akis, 2015). Globalization and the resulting fusion of world markets have created an extremely competitive and dynamic environment for organizations (Akis, 2015). To stay competitive in this environment, organizations need the capability to innovate (Ceausu et al., 2017), or as Urbancova (2013) states, are organizations at risk of lagging behind if they are not capable of introducing innovations on an ongoing basis. Already Tushman and Nadler (1986) stressed the importance of not only managing the success of the daily business but rather simultaneously creating innovation for tomorrow. Further, they mentioned that the management of innovation could be the most urgent managerial challenge. Today, this view seems to be still valid, as innovation is still regarded as an essential driver of economic performance not only in academic papers (Tohidi and Jabbari, 2012; Urbancova, 2013) but also by the maturity of CEOs as a survey of Accenture reveals 
(Alon, Elron and Jackson, 2015). The importance of innovation can be explained by the fact that goals such as increased productivity and profitability, the penetration of new markets, and the improvement of existing market shares are achieved through innovation activities, which are the reason for companies to commit to developing their capability to innovate (Dereli, 2015). As Tohidi and Jabbari (2012) state: "Innovation is the success key for organizations."

According to Tohidi and Jabbari (2012), innovation is not only the most important but at the same time, one of the most difficult issues organizations have to confront today. This point is supported, by an innovation survey of Alon et al. (2015), which results show that companies are very confident in their capability to innovate, which is not justified when compared to their actual innovation performance. They furthermore mention that this misjudgment leads to negative effects, since organizations, who believe themselves to be innovators, are less likely to take actions to improve their capability to innovate and that their leaders are also less likely to recognize the complexity in innovation. Another survey by Loewe and Dominiquini (2006) provides a more self-critical image of organizations, which, nonetheless, also struggle in developing their innovation capabilities. According to Loewe and Dominiquini (2006), the reason for the struggle is that most organizations do only treat the symptoms or single root causes of their innovation issues and that this procedure is ultimately likely to fail since isolated measured proof to be inefficient. Instead, organizations need to tackle innovation with a systematic and holistic approach (Loewe and Dominiquini, 2006). The results of these surveys are supported by Ceausu et al. (2017), who mention that despite the importance of innovation only a few companies have mastered managing it.

Concluding, to be a successful innovator an organization must first understand which factors determine its innovation capabilities. In addition, organizations need to be able to assess their current organizational innovation capability before planning specific measures to achieve the desired state. However, this paper's research has revealed the existence of a gap in the literature regarding the existing organizational innovation capability models. Each model analyzed is missing at least one of the following properties: holistic focus instead of just one specific dimension, clear definition and explanation of its dimensions, and appropriate self-assessment tool. Thus, existing models make it difficult for organizations to improve their organizational innovation capabilities. These challenges should be overcome by developing a method to assess organizational innovation capability. Therefore, this paper aims to identify the relevant factors that define the capability of an organization to innovate and to develop a maturity assessment method to assess the capability of an organization to innovate with the goal to create awareness of its strong and weak points as well as possible areas of improvement.

In order to fulfill this paper's objective, the following research question needs to be answered: How should a method be designed in order to assess an organization's capability to innovate?

This paper continues with a literature review of the existing theories and related work about innovation, innovation models, as well as organizational behavior by analyzing what behavior does enable innovation within an organization. Further, the applied methodology and the created organizational innovation capability model and maturity assessment are presented and explained. Finally, this paper closes with the conclusion and suggests areas for further research.

\section{EXISTING THEORIES AND RELATED WORK}

\subsection{Innovation and Existing Models}

Creativity is defined as the generation of new ideas, which are useful or serve a purpose and the instantiation of these creative ideas are defined as innovation, thus, innovation can be seen as the successful implementation of creative ideas (Amabile et al., 1996). Organizational innovation is therefore defined as the successful implementation of creative ideas within the organizational context (Sarros, Cooper and Santora, 2008; Gumusluǒlu and Ilsev, 2009).

An organization's capability to innovate is vital as innovation has become one of the more powerful factors for growth, performance, and valuation (Salavou, Baltas and Lioukas, 2004; Barsh, Capozzi and Davidson, 2008). Therefore, the question arises on how an organization can improve its innovation performance. Within the literature many organizational factors can be found, which support the innovation performance such as the organizational structure (Hunter and Cushenbery, 2011; Robbins and Judge, 2016), the organizational culture 
(Maughan, 2012; Szczepańska-Woszczyna, 2014) and appropriate leadership (Agbor, 2008; Sarros, Cooper and Santora, 2008; Gumusluŏlu and Ilsev, 2009). However, according to Loewe and Dominiquini (2006), it is not effective to adjust single factors but instead do organizations need to address innovation in a systematic and holistic approach in order to improve the innovation performance. Likewise, Mumford and Hunter (2005) do suggest a holistic view of how to foster organizational innovation. They mention that creative ideas may be generated by individuals but that for the successful implementation of these ideas the individuals need to be considered within a team. Moreover, it needs to be considered that these teams do function within broader structures such as divisions, departments, and organizations. Hunter and Cushenbery (2011) add that the multilevel perspective provides a more accurate and useful perspective on the innovative performance and they furthermore note that creativity and innovation are complex and nonlinear phenomena that are the result of a complex set of activities, actions, and behaviors and in order to achieve successful innovation, attention must be paid to this complexity (Hunter and Cushenbery, 2011). The multilevel approach is further supported by Robbins and Judge (2016) who also share the opinion that all three organizational levels are needed in order to successfully implement ideas and therefore create innovation.

The literature review revealed three relevant innovation models for the objective of this research paper. The Innovation Effectiveness model by Loewe and Dominiquini (2006) defines the following four dimensions, which are relevant for the effectiveness of innovation within an organization: leadership and organization, culture and values, people and skills, and processes and tools. Unfortunately, their report does not provide a detailed definition of the model's dimensions or what sub-topics they cover. In addition, the provided simplified maturity check does not allow an analysis of the maturity of each dimension but instead only provides a vague overall score of maturity.

The second innovation model, the Profile of Innovation Culture model from Losane (2013), defines innovation culture as the culture which makes innovation its everyday life and therefore supports a company's sustainability. This model consists of the five determinants values, strategy, structure, behavior and communication, and leadership for organizational culture and further provides, based on the determinants, the profile of innovation culture. Also, the model's author provides a definition of innovation culture as well as the characteristics based on an extensive literature review. However, the model is only focused on culture and it does not provide a deeper explanation of the characteristic or a possibility for a detailed self-assessment in order for an organization to determine its strengths and weaknesses.

This third innovation model, the Direct and Indirect Leadership Influence model from Hunter and Cushenbery (2011), focuses on leadership and its direct and indirect influences on the innovation process. The authors provide a multi-level innovation process and argue that innovation starts with a creative idea, which is born from individuals. These individuals do normally not operate alone and are part of a team. Within that team, ideas must be proposed and validated and if successful it may be adjusted or refined by the team and even be prototyped. If a prototype is viable, the next step is to implement it at the organizational level, where the project may shift to other teams within the organization for further refinement, testing, evaluation, or realization. In addition, Hunter and Cushenbery (2011) mention that these three stages are firstly not independent of each other and secondly, therefore, are not rigid. Also, they state that leaders can indirectly influence innovation by indirect methods such as creating an environment that allows novel thinking or that leaders can directly influence innovation by direct methods by e.g. allocating resources. The model from Hunter and Cushenbery (2011) is based on a solid literature base and reveals the importance of leadership as well as the methods which leaders can use to support innovation. However, its focus is only on leadership and furthermore does only partially explain how this leadership method can be used successfully. In addition, it lacks the possibility for an organization to assess itself.

\subsection{Organizational Behavior}

According to Robbins and Judge (2012) organizational behavior (OB) does examine the impact of individuals, groups, and structures on human behavior within an organization with the aim of influencing them positively and thereby increasing the effectiveness of the organization. Key elements of OB are therefore individual behavior, group behavior, and organization system behavior, which makes it a multi-level analysis of human behavior (Robbins and Judge, 2012). 
Within this chapter, the subtopics related to group behavior and organizational system behavior are analyzed while focusing on innovation. Individual behavior is not part of this research, because it is not relevant for the creation of the organizational innovation capability model.

\subsubsection{Group Behavior}

Group behavior can be broken down into the topics of groups and teams, power and politics, and leadership.

\section{Groups and Teams:}

A group is two or more interdependent and interaction individuals who share common interests or objectives and it can be of formal or informal nature (Robbins and Judge, 2012). A team is a group with members of complementary skills, furthermore does this kind of group share a common mission, performance goal, and approach for which they hold themselves mutually accountable (Katzenbach and Smith, 1993). The differences between a group and a team are therefore that group members mainly interact to share information while team members interact in a collaborative way in order to perform a collective performance while utilizing positive synergies (Robbins and Judge, 2012). To increase the innovative performance of groups and teams the following characteristics are of importance:

- Diversity: According to Hirschberg (1999), teams consisting of people from different departments (cross-functional-teams) improve overall creativity and innovation (Hirschberg, 1999). The same seems to apply to cultural diversity. Multi-cultural teams achieve higher levels of creativity than their counterparts. A challenge that diverse teams face is that their heterogeneousness makes it more difficult to integrate processes and problem-solving processes (Gressgård, 2011). According to Gibson and Gibbs (2006), however, could a psychologically safe communication climate help to mitigate these challenges.

- Team size: In order to improve the innovation performance of teams the team size should be kept small since too many members limit the idea exchange between the individuals (Hunter and Cushenbery, 2011) and small teams increase the individual commitment and performance (Gressgård, 2011). The optimal team size tends to be between five to nine people (Robbins and Judge, 2017).

- Team compositions: According to Sethi, Smith and Park (2001), social bonds within teams above a certain level reduce their innovation performance. In order to prevent the decrease of the innovation performance of teams over time, it is necessary to modify team compositions or that team members are involved in several teams (Gressgård, 2011).

- Personality of members: According to Robbins and Judge (2016) do especially teams with a high level of conscientiousness and openness, based on the Big Five personality model, not only perform better but are also more innovative.

\section{Power and Politics:}

The ability to influence someone is called power (Homans, 1958). And politics can be defined by using power. Or in other words, if an employee converts his powers into action he is being engaged in politics (Robbins and Judge, 2012). Othman (2008) differentiates organizational politics into a negative and positive side. The negative side describes politics which involves convenient and illegal behavior. This kind of politics is disapproved due to its ethical dilemmas and the workplace conflicts it generates (Cacciattolo, 2015). Positive politics are seen as a social function that is important to the success of an organization (Othman, 2008). Cacciattolo (2015) describes organizational politics as positive when it serves the organization's vision and objectives, fosters collaboration and is ethically balanced. She further mentions that positive organizational politics sometimes is a constructive necessary to bring together different competing interest groups. Therefore, positive organizational politics provide a benefit to the organization.

An organization's culture can influence political behavior within the organization. Characteristics of cultures that intensify negative politics are low level of trust, rare and unclear performance evaluations, zero-sum reward allocation practices, self-serving senior managers and the scarcity of resources (Robbins and Judge, 2016). The effect of organizational politics on innovation performance is, according to Abbas and Raja (2014), not been examined by any studies. Their research provided first insights that negative politics do not only hinder the productivity but also the innovation capability of an organization. 
Leadership:

According to Yukl (2006) leadership is the process of influencing others so in order to understand and agree on action to be taken and methods to be used, as well as the facilitation of individual and collective efforts to achieve common goals. The differences of power and leadership are that leadership uses power to achieve group goals and that power is directed downwards to influence the followers and not upwards or lateral. Leadership is seen as a significant factor for innovation (Gumusluǒlu and Ilsev, 2009; Hunter and Cushenbery, 2011). According to Ancona and Caldwell (1987) especially the leadership style transformational leadership does support and promote innovation. This is supported by several studies, which have shown the positive influences of transformational leadership on organizational innovation (Gumusluǒlu and Ilsev, 2009). According to Sarros et al. (2008), transformational leadership helps to build a strong culture and does positively influence a positive climate for organizational innovation and therefore influence innovative behavior. The transformational leadership style is defined by four components: vision, role model, individual support, and intellectual stimulation (Gumusluǒlu and Ilsev, 2009).

\subsubsection{Organizational System Behavior}

The topic of organizational system behavior consists of the topics of organizational structure, organizational culture, and organizational change.

Organizational structure:

The organizational structure defines the way tasks are divided, grouped, and coordinated. According to the model of Mintzberg (1979), there are nine design parameters that determine the design of an organizational structure. By design, it means how the division of labor and coordination mechanisms influence the flow of materials, authority, information, and decision-making processes through the organization (Mintzberg, 1979). There are two extremes when designing an organizational structure, the mechanistic model and the organic model. The mechanistic model focuses on high specialization, high formalization, high centralization, high standardization, strong and tall hierarchy, and low complexity, while the organic model is the exact opposite. It is characterized by cross-functional and cross hierarchical teams, decentralization, and low formalization (Mintzberg, 1979).

Organizations that focus on innovation need the flexibility of an organic structure defined by its loose structure, low specialization and formalization and decentralization (Robbins and Judge, 2017) which provides employees with the autonomy and freedom to achieve tasks the way they see fit (Losane, 2013). Conversely, mechanical designs like the bureaucracy have a negative impact on creativity and innovation because they limit employees in their freedom to do their work and therefore inhibit creativity and innovation (Hunter and Cushenbery, 2011; Maughan, 2012).

\section{Organizational culture:}

Organizational culture can be defined as shared perceptions of organizational work practices within organizational units, which may vary compared to other organizational units (Van Den Berg and Wilderom, 2004). Warrick and Mueller (2015) describe culture as the characteristic of a group of people defined by their beliefs, values, attitudes, behaviors, and practices. The term organizational culture is typically used to refer to the culture of a whole organization or any unit of people working together within an organization (Linnenluecke and Griffiths, 2010). Organizational culture is an important factor to drive and maintain innovation and therefore increase the innovativeness of an organization (Barsh, Capozzi and Davidson, 2008; Ceausu et al., 2017). According to Maher (2014), there are seven key dimensions to culture, which distinguish highly innovative organizations from others, which according to Szczepańska-Woszczyna (2014) can be used in order to assess and improve the organizational culture for innovation. The seven key dimensions, defined by Maher (2014), are risk-taking, resources, knowledge, goals, rewards, tools, and relationships.

\section{Organizational change:}

There are two kinds of change in organizations: planned and unplanned (Nelson and Quick, 2011). The planned organizational change is a deliberate action to bring an organization from its present state to a desired future state (Harigopal, 2006). For this type of change, proactive and carefully planned action can be pursued (Nelson and Quick, 2011). According to Robbins and Judge (2016), innovations are a specialized kind of change. Therefore, all innovations imply change but not all changes need to be seen as an innovation. Furthermore, in order to create an innovative climate, an organization may develop a culture for change. This means a change of mindset where instead to adapt to change an organization focuses on a proactive approach and embraces change by transforming its culture. 


\section{METHODOLOGY}

This paper uses the Design Science Research approach which is according to Hevner and Chatterjee (2010) suitable if the desired result is an artifact like a model or method, which is the case in this paper. Also, the approach allows developing the artifact in an iterative manner in order to include further insights from the data collection as soon as it is gathered, which for this research were done three iterations. Furthermore, it allows a qualitative data collection which is the data collection technique for this research.

In order to answer the research question of how a method should be designed in order to assess an organization's capability to innovate, this paper uses secondary and primary data. The secondary data consists of artifact and document studies, while the primary data is based on the results of nine semi-structured expert interviews. Eight of these interviews are conducted with five innovation experts in the fields of production, technology, banking, and consulting and one with an expert in applied organizational psychology. The semi-structured interviews with the innovation experts are used to improve and validate the Organizational Innovation Capability Model and its corresponding questionnaire while the interview with the expert in applied organizational psychology is used for the improvement and validation of the questionnaire from a usability perspective. As suggested by Saunders et al. (2009) the authors of this work used existing contacts from their own social networks to gain access to the intended interview partners.

\section{ORGANIZATIONAL INNOVATION CAPABILITY MATURITY MODEL}

The developed maturity model consists of the Organizational Innovation Capability Model and a corresponding questionnaire. The Organizational Innovation Capability Model and the questionnaire are based on the literature review and expert interviews and the final version has been reached after three development iterations. As illustrated in Figure 1, the model consists of seven dimensions with a total of twenty-seven indicators. The dimension Organizational Structure aims to evaluate if an organization provides the necessary structures needed in order to support innovation. The dimension Leadership assesses if the current leadership style motivates and supports people in order to create innovation. The third dimension Power \& Politics does analyze if politics within an organization support innovation or hinder it. The dimension Collaboration evaluates the way people within an organization work together. The dimension Organizational Change assesses the attitude of an organization towards change. The dimension Organizational Innovation Management does analyze how an organization manages the innovation process inside and outside of the organization. The last dimension is called Organizational Culture and assesses the maturity by using Maher's (2014) model and its seven key dimensions for an organizational culture for innovation.

The comparison with the existing models from the literature revealed that the developed model provides a more detailed and comprehensive set of indicators to analyze the organizational innovation capability of an organization, while also covering all indicators of the existing models, except for three indicators, which did not match the requirements for the Organizational Innovation Capability Model.

The maturity model provides four maturity levels, one to four while one is the lowest and four the highest. The maturity level of an organization is determined by the answers given in the questionnaire. The questionnaire does not work with the common Likert scale but instead uses a single indicator description for each indicator and provides four level descriptions for the user to choose from. This approach allows the user to simply pick the level description, which fits the most to his or her current situation. An excerpt from the questionnaire is shown in Table 1. 


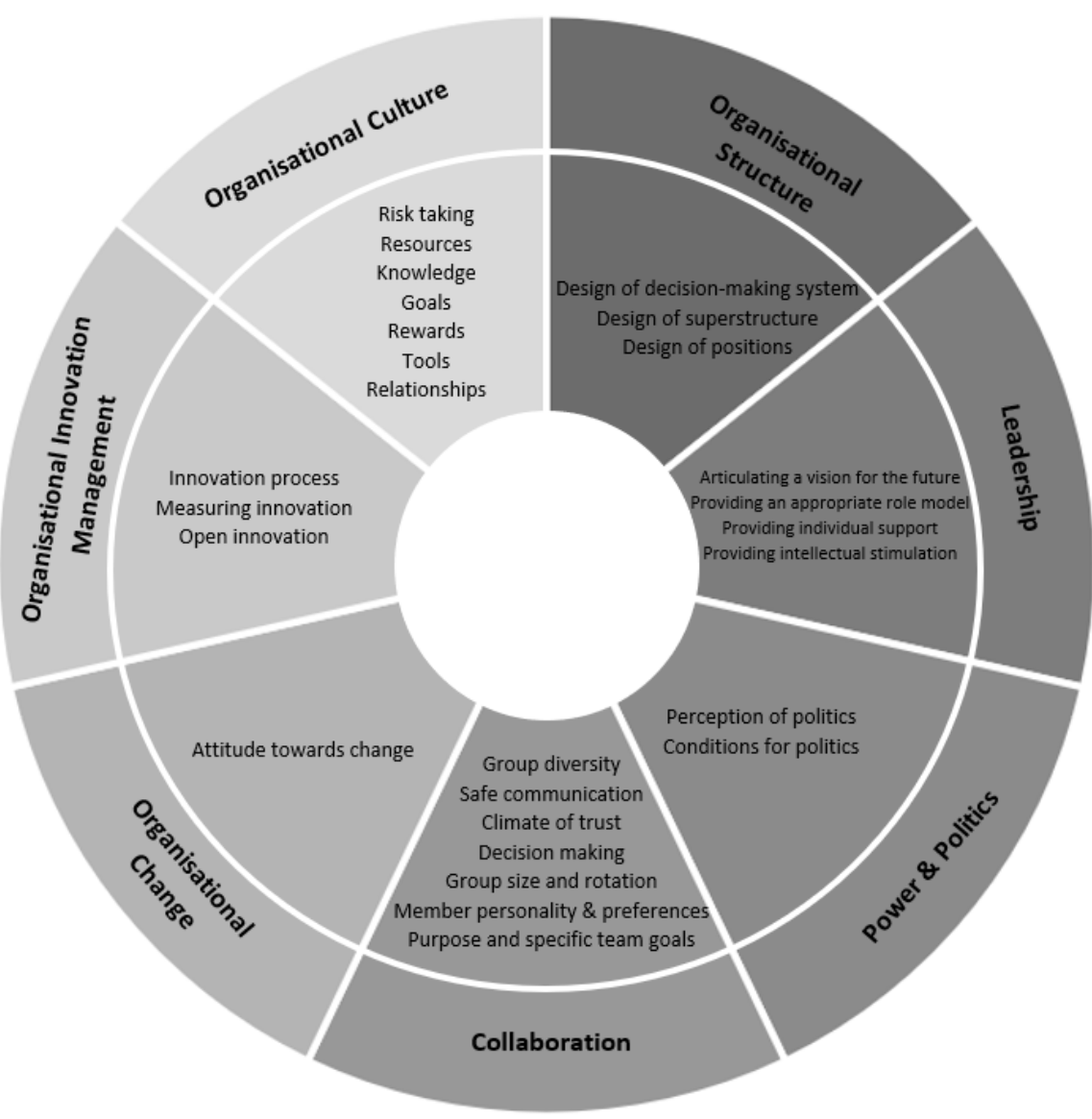

Figure 1. Organizational Innovation Capability Model

Table 1. Example excerpt of the questionnaire

\begin{tabular}{|c|c|c|c|c|c|c|}
\hline Dimension & Indicator & Description & Level 1 & Level 2 & Level 3 & Level 4 \\
\hline $\begin{array}{l}\text { Organi- } \\
\text { sational } \\
\text { Structure }\end{array}$ & $\begin{array}{l}\text { Design of } \\
\text { positions }\end{array}$ & $\begin{array}{l}\text { Describes how } \\
\text { much freedom } \\
\text { do people have } \\
\text { in the way they } \\
\text { perform their } \\
\text { jobs. }\end{array}$ & $\begin{array}{l}\text { Job are highly } \\
\text { specialised and } \\
\text { standardised. }\end{array}$ & $\begin{array}{l}\text { The organisation } \\
\text { is on the way to } \\
\text { reduce job } \\
\text { standardisation } \\
\text { and enriched } \\
\text { jobs. }\end{array}$ & $\begin{array}{l}\text { Jobs require } \\
\text { broad knowledge } \\
\text { and skillset and } \\
\text { encourages } \\
\text { employees to } \\
\text { come up with } \\
\text { their own } \\
\text { solutions. } \\
\end{array}$ & $\begin{array}{l}\text { Employees can } \\
\text { have several } \\
\text { roles within the } \\
\text { organisation and } \\
\text { are actively } \\
\text { encouraged to } \\
\text { acquire new } \\
\text { skills. }\end{array}$ \\
\hline
\end{tabular}

Once the individual or better several employees from different units of an organization have completed the questionnaire, it can be evaluated. The evaluation provides an overview of each dimension and its corresponding maturity level. The maturity level of each dimension is calculated by the average score of the underlying indicators. Each indicator on maturity level 1 achieves one point, on maturity level 2 two points and so on. The evaluation across all dimensions dispenses with an overall maturity level, as the various dimensions have different numbers of indicators.

The feedback during the expert interviews for the testing cycle was positive. The interviewees mentioned that the model and questionnaire are very comprehensive and that especially due to the possibility of comparing the maturity of different units within the organization this model provides significant value for an organization. Furthermore, the interviewees mentioned that this analysis can be useful for organizations to create awareness for the topic of innovation and to provide a good starting point for further discussions and actions throughout the company. 


\section{CONCLUSION}

The literature research has identified that the analyzed existing innovation models have several weaknesses, be it the lack of a holistic focus, the lack of precise and understandable indicators, or the lack of appropriate self-assessment tools. Therefore, the objective of this paper was to develop an organizational innovation capability maturity model, which helps organizations to assess their innovation capability and with that supports their innovation efforts and to thereby answers the following research question.: How should a method be designed in order to assess an organization's capability to innovate?

Based on the literature review and expert interviews the Organizational Innovation Capability Model was developed, including seven dimensions with a total of twenty-seven indicators. Furthermore, a corresponding questionnaire with a total of twenty-seven questions has been developed. For each indicator, a question exists, which defines the maturity level of this indicator. The combination of the model and the questionnaire results in the maturity assessment of organizational innovation capability.

The research was able to answer the research question and could therefor successfully achieve the research objective. The results show that the developed model and questionnaire not only cover all dimensions and almost all indicators of the existing models from the literature but further provides additional dimensions and indicators. This research argues that the additional dimensions and indicators are needed in order to provide a comprehensive overview of the organizational innovation capability maturity of an organization. Further was the validity and value of the maturity model confirmed during the expert interviews. The questioned experts especially emphasized its value for creating awareness within an organization and providing a good foundation for further discussions and actions.

The authors of this paper suggest the following two further areas of research. Firstly, future studies could examine the relationships of dimensions and their mutual influence in more detail. Particularly interesting would be to find out which dimensions and indicators are active variables (do influence others) and which are passive variables (are influenced by others). This would allow a better understanding of the impact of each dimension and indicator on the innovation capability of an organization. This knowledge would help to identify the most critical indicators and provide valuable indications of where measures should be taken. Secondly, future studies could research how specific measures could be proposed to organizations based on their maturity level. This would enhance this maturity model by providing organizations not only with a maturity assessment but further with clear instructions on how to improve. The need for this future research is given by the expert interview results, where this feature was mostly mentioned as a useful future extension of the model. The extraordinary challenge here will be that, as Maughan (2012) mentioned, there is no silver bullet for innovation, due to the huge differences between organizations and their environment.

\section{REFERENCES}

Abbas, M. and Raja, U. (2014) 'Impact of Perceived Organizational Politics on Supervisory-Rated Innovative Performance and Job Stress: Evidence from Pakistan', Journal of Advanced Management Science, 2(2), pp. 158-162. doi: 10.12720/joams.2.2.158-162.

Agbor, E. (2008) 'Creativity and innovation: The leadership dynamics', Journal of Strategic Leadership, 1(1), pp. 39-45.

Akis, E. (2015) 'Innovation and Competitive Power', Procedia - Social and Behavioral Sciences. Elsevier B.V., 195, pp. 1311-1320. doi: 10.1016/j.sbspro.2015.06.304.

Alon, A., Elron, D. and Jackson, L. (2015) Innovation: clear vision, cloudy Execution, Accenture. Available at: https://www.accenture.com/t20160412T084615Z__w_/us-en/_acnmedia/PDF-10/Accenture-Innovation-ResearchExecSummary.pdf\#zoom=50.

Amabile, T. M. et al. (1996) 'Assessing the Work Environment for Creativity', The Academy of Management Journal, 39(5), pp. 1154-1184.

Ancona, D. G. and Caldwell, D. F. (1987) 'Management issues facing new product teams in high technology companies', in Advances in Industrial and Labor Relations. JAI Press Inc., pp. 199-221.

Barsh, J., Capozzi, M. M. and Davidson, J. (2008) 'Leadership and innovation', in The McKinsey Quartlerly, pp. 38-47. Benoit, G. (2008) Innovation: the History of a Category, Project on the Intellectual History of Innovation Working.

Van Den Berg, P. T. and Wilderom, C. P. M. (2004) 'Defining, measuring, and comparing organisational cultures', Applied Psychology, 53(4), pp. 570-582. doi: 10.1111/j.1464-0597.2004.00189.x. 
Cacciattolo, K. (2015) 'Organisational Politics: the Positive \& Negative Sides', European Scientific Journal, 11(1), pp. $1857-7881$.

Ceausu, I. et al. (2017) 'The Organizational Culture As a Support of Innovation Processes', International Journal of Advanced Engineering and Management Research, 2(6), pp. 2392-2403. Available at: www.ijaemr.comhttp://ijaemr.com/.

Dereli, D. D. (2015) 'Innovation Management in Global Competition and Competitive Advantage', Procedia - Social and Behavioral Sciences. Elsevier B.V., 195, pp. 1365-1370. doi: 10.1016/j.sbspro.2015.06.323.

Gibson, C. B. and Gibbs, J. L. (2006) 'Unpacking the concept of virtuality: the effects of geographic dispersion, electronic dependence, dynamic structure, and national diversity on team innovation', dministrative Science Quarterly, 51(3), pp. 451-495.

Gressgård, L. J. (2011) 'Virtual team collaboration and innovation in organizations', Team Performance Management, 17(1), pp. 102-119. doi: 10.1108/13527591111114738.

Gumusluǒlu, L. and Ilsev, A. (2009) 'Transformational leadership and organizational innovation: The roles of internal and external support for innovation', Journal of Product Innovation Management, 26(3), pp. 264-277. doi: 10.1111/j.15405885.2009.00657.x.

Harigopal, K. (2006) Management of Organizational Change: Leveraging Transformation. 2. SAGE PUBN.

Hevner, A. and Chatterjee, S. (2010) Design Research in Information Systems. New York: Springer.

Hirschberg, J. (1999) The creative priority: Putting innovation to work in your business. New York: Harper-Business.

Homans, G. C. (1958) 'Social Behaviour as Exchange', American Journal of Sociology, 63, pp. 597-606.

Hunter, S. T. and Cushenbery, L. (2011) 'Leading for innovation: Direct and indirect influences', Advances in Developing Human Resources, 13(3), pp. 248-265. doi: 10.1177/1523422311424263.

Katzenbach, J. R. and Smith, D. K. (1993) 'The Discipline of Teams', Harvard Business Review, 71, pp. 111-120.

Linnenluecke, M. K. and Griffiths, A. (2010) 'Corporate sustainability and organizational culture', Journal of World Business. Elsevier Inc., 45(4), pp. 357-366. doi: 10.1016/j.jwb.2009.08.006.

Loewe, P. and Dominiquini, J. (2006) 'Overcoming the barriers to effective innovation', Strategy and Leadership, 34(1), pp. 24-31. doi: 10.1108/10878570610637858.

Losane, L. (2013) 'Innovation Culture - Determinant of Firms ' Sustainability', World Academy of Science, Engineering and Technology International Journal of Social, Behavioral, Educational, Economic, Business and Industrial Engineering Vol:7, No:10, 2013, 7(10), pp. 2755-2760.

Maher, L. (2014) 'World Hospitals and Health Services', The Offical Journal of the International Hospital Federation, 50(1), pp. 4-6.

Maughan, C. (2012) Organisational Innovation: A review of the literature. Working Paper CW001. doi: 10.1142/9789813220607 0010.

Mintzberg, H. (1979) The structuring of organizations. Prentice-Hall. Available at: http://citeseerx.ist.psu.edu/viewdoc/download?doi=10.1.1.383.6417\&rep=rep1\&type=pdf.

Mumford, M. D. and Hunter, S. T. (2005) 'Innovation in Organizations: A Multi-Level Perspective on Creativity', Research in Multi-Level Issues, 4(October), pp. 9-73. doi: 10.1016/S1475-9144(05)04001-4.

Nelson, D. L. and Quick, Ja. C. (2011) Organizational Behavior - Science, the Real World, and You. 7. Mason, OH 45040: South-Western Cengage Learning.

OECD (2005) 'The measurement of scientific and technological activities', Oslo manual, pp. 1-92. Available at: http://www.oecd.org/science/inno/2367614.pdf.

Othman, R. (2008) 'Organisational politics: The role of justice, trust and job ambiguity', Singapore Management Review, 30(1), pp. 43-53.

Robbins, S. P. and Judge, T. A. (2012) Essentials of Organizational Behavior. 12. Essex: Pearson Education.

Robbins, S. P. and Judge, T. A. (2016) Essentials of Organizational Behavior. 13. Essex: Pearson Education Limited.

Robbins, S. P. and Judge, T. A. (2017) Organizational Behavior. 17. Essex: Pearson Education Limited.

Salavou, H., Baltas, G. and Lioukas, S. (2004) 'Organisational innovation in SMEs: The Importance of Strategic Orientation and Competitive Structure', European Journal of Marketing, 38(9/10), pp. 1091-1112. doi: 10.1108/03090560410548889.

Sarros, J. C., Cooper, B. K. and Santora, J. C. (2008) 'Building a Climate for Innovation Through Transformational Leadership and Organizational Culture', Journal of Leadership \& Organizational Studies, 15(2), pp. 145-158.

Saunders, M., Lewis, P. and Thornhill, A. (2009) Research Methods for Students. 5., Research methods for business students. 5. Essex: Pearson Education Limited. doi: 10.1007/s13398-014-0173-7.2.

Sethi, R., Smith, D. C. and Park, C. W. (2001) 'Cross-functional product development teams, creativity and the innovativeness of new consumer products', Journal of Marketing Research, 38(1), pp. 73-85. 
Szczepańska-Woszczyna, K. (2014) 'The importance of oranizational culture for innovation in the company', Forum Scientiae Oeconomia, 2(3).

Tohidi, H. and Jabbari, M. M. (2012) 'The important of Innovation and its Crucial Role in Growth, Survival and Success of Organizations', Procedia Technology, 1, pp. 535-538. doi: 10.1016/j.protcy.2012.02.116.

Tushman, M. and Nadler, D. (1986) 'Organizing for Innovation', California Management Review, 28(3), pp. 74-92. doi: https://doi.org/10.2307/41165203.

Urbancova, H. (2013) 'Competitive Advantage Achievement through Innovation and Knowledge', Journal of Competitiveness, 5(1), pp. 82-96. doi: 10.7441/joc.2013.01.06.

Warrick, D. D. and Mueller, J. (2015) 'Understanding, Building and Changing Organization Culture', in Lessons in changing cultures: Learning from real world cases, pp. 1-16.

Yukl, G. (2006) Leadership in organisations. 6. London: Pretice Hall. 